\title{
La educación moral. Fundamentación fillosófica y calado actual de las ideas ético-pedagógicas de Émile Durkheim
}

\section{Moral education. Philosophical foundation and current draft ethical and pedagogical ideas of Emile Durkheim}

\author{
Domingo FERNÁNDEZ AGIS \\ Universidad de La Laguna
}

Recibido: Octubre 2011

Aceptado: Diciembre 2011

\section{Resumen}

La cuestión clave que Durkheim aborda y desarrolla en sus escritos sobre la educación moral gira en torno a las dificultades que presenta encontrar las formas más adecuadas para conseguir la conciliación entre la autonomía personal de los individuos, que constituye un elemento irrenunciable en las sociedades modernas, y el carácter imperativo-constrictivo de las reglas colectivas en las que se estructura la moral vigente en esas mismas sociedades. La importancia de resolver eficazmente este asunto queda clara desde el momento en que Durkheim nos hace ver la necesidad de otorgar un fundamento moral a la acción social de los individuos.

En este trabajo nos proponemos revisitar las ideas éticas y pedagógicas de Durkheim, sopesando su posible operatividad en la situación actual.

Palabras clave: Durkheim, educación, moral, sociedad, política.

\begin{abstract}
The key issue addressed and developed in Durkheim's writings on moral education revolves around the difficulties of finding the best ways to achieve balance between personal autonomy of individuals, which is an indispensable element in modern societies, and mandatoryconstricting rules of collective structure in which the moral force in these same societies. The importance of effectively solving this issue is clear from the moment that Durkheim makes us see the need to provide a moral foundation for social action of individuals.

In this paper we propose to revisit the ideas of Durkheim, pondering its possible operation in the current situation.
\end{abstract}

Keywords: Durkheim, education, morals, society, politics. 
La cuestión central que Durkheim aborda y desarrolla en sus escritos sobre la educación moral no es otra que las dificultades que presenta encontrar formas adecuadas para conseguir la conciliación entre la autonomía personal de los individuos, que constituye un elemento irrenunciable en las sociedades modernas, y el carácter imperativoconstrictivo de las reglas colectivas en las que se estructura la moral vigente en esas mismas sociedades.

El trasfondo de su interpretación de la sociedad nos lo proporciona una concepción organicista, en la cual la moral viene a ocupar un lugar de privilegio, constituyendo una pieza esencial para el mantenimiento y buen funcionamiento del orden social.

Sobre el origen del organicismo sostenido por Durkheim, Anthony Giddens ha hecho notar la importancia de la influencia derivada de los progresos de la Biología a lo largo del siglo XIX y, de forma muy especial, del darwinismo. Estos fueron sin duda factores que ejercieron un influjo considerable sobre Durkheim ${ }^{1}$. Por otra parte, la heterogeneidad de las influencias a las que se muestra receptivo, le sirve para distinguirse de su entorno cultural inmediato e ir delimitando un camino propio, que le conducirá a la elaboración de una teoría original, al margen de las dos únicas opciones éticas aceptadas de forma general como válidas en su época: el utilitarismo y el idealismo kantiano ${ }^{2}$.

Para Durkheim, la moral, a pesar de su necesaria interiorización por parte de los individuos, es en realidad una propiedad de la colectividad, es algo que pertenece a la sociedad, un rasgo definitorio y una característica esencial de la misma. Por ello se opone a los enfoques individualistas, deudores de la economía ortodoxa, que ven sólo actores individuales en la explicación de los fenómenos colectivos ${ }^{3}$. A su juicio, las acciones morales tienen dos aspectos. Por un lado, suponen la existencia de un ideal o ideales, que ejercen una atracción sobre los individuos. De otro, conllevan una coacción sobre el comportamiento individual ${ }^{4}$. No obstante, la coerción es para él un aspecto secundario, externo, frente a la cualitativa importancia inductora de la autoridad moral, que Durkheim considera el elemento interno y determinante ${ }^{5}$. El mantenimiento del valor de la autoridad moral ha de estar enraizado en los sentimientos colectivos. Se entiende por ese motivo que, tal como él sostiene, "la función del castigo consiste en mantener estos sentimientos con el mismo grado de intensidad: si no se castigaran las transgresiones, no se mantendría el sentimiento con la firmeza necesaria para la unidad social" ". Sin embargo, esta realidad no hace, como ya apuntábamos, de los aspectos coactivos los elementos decisivos de la moralidad. Esta convicción resulta decisiva en su enfoque de la educación moral.

Las reglas morales están vinculadas a las condiciones sociales de vida, por ello corresponden a una época y lugar determinados. Frente a esto, Durkehim evoca cómo los

${ }^{1}$ Giddens, A. (1977). El capitalismo y la moderna teoría social. Barcelona: Labor, pp. 128-9.

2 Ibídem, p. 131.

3 Ibídem, p. 132.

${ }^{4}$ Ibídem, p. 135.

${ }^{5}$ Ibídem, 164.

${ }^{6}$ Ibídem. 
filósofos siempre pretendieron "enunciar principios morales universales, pero en realidad actuaron como precursores y progenitores de cambios inmanentes en su sociedad"7. En las sociedades modernas dichas condiciones han evolucionado en una dirección concreta, produciéndose una creciente expansión del individualismo, vinculada, según piensa él, a una progresiva división del trabajo. Se añade a esto la pérdida de influencia social de las creencias religiosas tradicionales, dando lugar todo ello al vacío moral que caracteriza en opinión de Durkheim a estas sociedades ${ }^{8}$. Todas estas circunstancias plantean enormes retos educativos y, de forma muy particular, dificultan el desarrollo de una labor efectiva en el terreno de la educación moral. La educación, para él, es una tarea eminentemente social, pues a través de ella, no sólo se trata de formar a los individuos para que adquieran ciertas habilidades y competencias, sino de realizar en ellos el ideal que, en última instancia, otorga un fundamento moral a la sociedad a que pertenecen ${ }^{9}$. En resumen, para Durkheim, la educación crea algo que tan sólo de forma incipiente existe antes de ella aparezca: el ser social ${ }^{10}$.

\section{Las reflexiones de Durkheim sobre la educación moral. Relaciones con sus consi- deraciones a propósito del Estado}

La elaboración de La educación moral tiene lugar a lo largo de los años 1901 y 1902. Aproximadamente de esas mismas fechas, en concreto entre 1900 y 1905 , data la preparación del pequeño ensayo de Durkheim, "El Estado", que fue publicado póstumamente, en 1958, por la Revue philosophique. Tomar en consideración las ideas maestras de este texto resulta interesante para enmarcar, en un contexto de reflexión más amplio, eminentemente político en este caso, los planteamientos básicos de $L a$ educación moral.

El enfoque sociológico al que este autor somete todas las cuestiones que analiza se hace evidente desde el momento en que Durkheim considera que "el Estado no crea la vida colectiva, del mismo modo que el cerebro no crea la vida del cuerpo, ni es la causa primera de la solidaridad que une a las diversas funciones. Puede haber, y en efecto

${ }^{7}$ Ibídem, p. 168.

${ }^{8}$ Ibídem, p. 199.

${ }^{9}$ Sin embargo, se ha señalado que, "mientras para Durkheim la educación obedece a un proyecto político de preservar lo mejor de la cultura que la sociedad ha acumulado, y transmitirlo a las nuevas generaciones, en Bourdieu, hay más bien una noción de la educación como reproductora de la desigualdad en la distribución del capital cultural, el cual además se ha seleccionado y plasmado en los planes escolares de manera arbitraria, beneficiando a aquellos que en su socialización primaria, respectiva a su clase, han estado más familiarizados con ese capital cultural, creando mitos como el de don o aptitud e inaptitud natural”. Morales Zúñiga, L. C. (2009). "Durkheim y Bourdieu: reflexiones sobre la educación". Reflexiones. Vol. 88, n 1, p. 160.

${ }^{10}$ Durkheim, E., "La educación como fenómeno social", L'Année Sociologique, vol. VII, 1904, pp. 684-686. 
hay, sociedades políticas sin Estado. En ellas la cohesión es producida por creencias diseminadas en todas las consciencias, que las mueven de manera oscura" ${ }^{11}$.

Este planteamiento no le impide reconocer la importancia del Estado ni defender su función rectora en las sociedades complejas. Frente a aquellas sociedades en las que la cohesión social encuentra su fundamento en creencias que es imposible articular en un sistema coordinado ni fundamentar de manera racional, la organización estatal crea y refuerza mecanismos racionales para afianzar la acción eficiente de los individuos. Entendiendo, claro está, que no hay oposición entre los intereses de éstos y los generales de la sociedad. Por eso, para él, "el Estado es (...) antes que nada, un órgano de reflexión"12. Sus tareas son equiparables, en este esquema organicista tan característico al que recurre, a las que debe realizar el cerebro en relación al cuerpo. El Estado debe controlar y dirigir, pero tales cometidos no pueden llevarse a buen término haciendo uso tan sólo de los instrumentos de represión que los poderes del Estado tienen a su alcance. Durkheim insiste siempre en la importancia vital de aquellos recursos que provienen de la misma sociedad, entre ellos la propia moral, que él entiende como una potencia esencialmente persuasora. Por otra parte, que la acción del Estado se decante hacia una utilización cada vez mayor de estos recursos, es un signo del progreso social, ya que, "en la historia, la acción del Estado puede ser muy diferente: una es exterior, la otra es interior. La primera está constituida por manifestaciones violentas, agresivas; la otra es esencialmente pacífica y moral.

Cuanto más nos remontamos en el pasado, más aparece la primera como preponderante" 13 .

Pero, más allá del uso de la fuerza tan recurrente en sus orígenes, el gran objetivo de la acción del Estado consiste en hacer posible el acceso de los ciudadanos a unos niveles de seguridad y progreso que serían inconcebibles sin la presencia de éste. Se entiende así que el Estado pueda llegar a ser "el órgano de la justicia social", y que a través de él sea posible organizar "la vida moral del país"14. La primera de estas expresiones nos remite a sus presupuestos organicistas. La segunda, a una concepción social de la moralidad que pretende actuar como antídoto del excesivo individualismo que él detecta en la sociedad de su tiempo. En cualquier caso, en su opinión, ninguno de estos cometidos sería abordable sin una eficiente y generalizada praxis en el terreno de la educación moral.

Durkheim entiende que recapacitar sobre todo esto resulta crucial en la coyuntura histórica en la que él elabora sus reflexiones, ya que considera que se ha producido en esos momentos una característica inversión de los términos en los que se concebía la

${ }^{11}$ Durkheim, E. "L'État". Revue Philosophique, no 148, pp. 433-7. En este trabajo, para facilitar las consultas al lector, citaremos la obra siguiendo la versión española a que hacemos referencia a continuación. Durkheim, E., "El Estado", en Durkheim E. (2011). Escritos politicos. Barcelona: Gedisa, p. 62.

12 Ibídem, p. 63.

${ }^{13}$ Ibídem, p. 63.

${ }^{14}$ Ibídem, p. 64. 
relación del individuo y la sociedad. De esta forma, "mientras que en el origen la persona humana carecía de valor, hoy día es la cosa sagrada por excelencia y todo atentado dirigido contra ella nos produce el mismo efecto que los atentados dirigidos contra las divinidades favorables a los fieles de las religiones primitivas" ". Puesto que, desde entonces, tal tendencia no ha hecho sino acentuarse, podemos considerar que su análisis, salvadas las peculiaridades expresivas que lo singularizan, es en este punto tan válido o más para nuestra sociedad ${ }^{16}$.

$\mathrm{Su}$ línea de reflexión es nítida y acentúa tanto los aspectos positivos de la existencia del Estado como los riesgos a que puede conducir su hipertrofia. Considera, en efecto, que el Estado despliega mecanismos para captar las necesidades colectivas y tratar de que la satisfacción de estas quede por encima de cualquier interés particular. Si bien, el propio cumplimiento de estos objetivos le hace crecer en tamaño y complejidad, por lo que "también necesita ser contenido por el conjunto de las fuerzas secundarias que le están subordinadas; sin ello, como todo órgano al que nada detiene, se desarrolla sin medida y se vuelve tiránico. No por eso deja de ser cierto que, en las sociedades complejas, es el instrumento necesario por medio del cual se realiza la igualdad y, por consiguiente, la justicia""17.

Todo esto le conduce a cuestionar y desautorizar la interpretación que hace del Estado el mayor enemigo de la libertad de los individuos. Por el contrario, en su opinión, puede ser el más eficaz aliado de la misma. Sus ideas están, en consecuencia, muy alejadas del credo liberal, pues entiende que "cuanto más fuerte y activo se vuelve el Estado, más libre se hace el individuo. Es el Estado quien lo libera. Nada es pues más funesto que despertar en el niño y mantener en el hombre adulto esos sentimientos de desconfianza y recelo con respecto al Estado, como si fuese la obra del individuo mientras que es su protector natural, el único protector posible" ${ }^{\prime 18}$. En efecto, al contrario de lo que cierta idealización del estado de naturaleza nos lleva a pensar, en aquellas sociedades en las que el Estado no existe o lo hace de manera incipiente, la autonomía

${ }^{15}$ Ibídem, p. 65.

${ }^{16}$ Señalemos, a este respecto, que hoy es usual la contraposición de los puntos de vista de Durkheim y Piaget, en relación a la educación moral. Se considera de este modo que Durkheim pone el acento en la importancia de la educación moral para conseguir la integración social de los individuos, mientras que Piaget pondría ante todo de relieve el objetivo de lograr, a través de ella, individuos capaces de integrar en su personalidad una interpretación, construida por ellos mismos, de los principios de la moral. Véase, por ejemplo, Neng Lin, W. - Enrigt, R. - Klatt, J. (2011). "Forgiveness as character education for children and adolescents". Journal of Moral Education, vol. 40, $\mathrm{n}^{\mathrm{o}}$ 2. June, p. 239.

Sin embargo, es necesario señalar que la posición característica de Durkheim se sitúa más bien en la búsqueda de un equilibrio entre ambas orientaciones. Curiosamente, hacia el énfasis en ese punto de equilibrio, siguiendo para ello a W. Damon, orientan la tesis central de su artículo los autores hace un momento citados.

${ }^{17}$ Durkheim, E., “El Estado", Durkheim E.. Escritos políticos. Edic. Cit., p. 66.

${ }^{18}$ Ibídem, p. 66. 
personal es irrealizable, estando los individuos obligados en todo momento a someterse a los dictados del colectivo ${ }^{19}$.

Nos enfrentamos, por tanto, a la siguiente paradoja: el Estado es percibido con frecuencia como opresor cuando, en realidad, puede ser el medio más eficaz para la protección de los derechos de los individuos, frente a las tendencias dominadoras de los poderes que trascienden ampliamente su ámbito de acción y la esfera de posibles situaciones sometidas a su control. Habría que decir, a este respecto, que sobran argumentos históricos para apoyar lo primero, aunque no carezcamos de recursos para acudir asimismo en apoyo de lo segundo. En efecto, existen aspectos en el liberalismo que siguen siendo hoy plenamente asumibles, pues tienen como objetivo último evitar la intromisión en la vida de los individuos de un poder que, dejado a su impulso original, destruiría los fundamentos de su libertad. Sin embargo, la sensibilidad de Durkheim se inclina a poner más el acento sobre otros peligros, para nosotros bien conocidos, que tienen que ver con la conversión de la libertad en una ilusión, cuando se hace de ésta sinónimo del libre juego de los poderes económicos, en una sociedad en la que el Estado pasa a ser un mero árbitro y un garante de los intereses de los más poderosos. La utopía democrática persigue, en todo caso, la instauración de un Estado que sea la mayor garantía con la que cuentan los ciudadanos para hacer efectivos sus derechos civiles y políticos ${ }^{20}$. La posibilidad de una autonomía moral, respetuosa en relación a una serie de valores básicos asumidos de forma colectiva y abierta a la posibilidad del mutuo reconocimiento del valor moral de los individuos ${ }^{21}$ descansa, en último término, en la existencia de un modelo de organización estatal que asume funciones que van más allá del mero arbitraje en los conflictos económicos ${ }^{22}$. Como hemos visto, a ella se sumaba ya Durkheim con las reflexiones que nos da a conocer en su escrito "El Estado".

${ }^{19}$ La propia disidencia, cuyo valor moral es incuestionable, tan sólo tiene sentido en relación a las formas de organización colectiva, cuya máxima expresión es el Estado. Para un análisis de la cuestión, desde el punto de vista de la educación moral, puede verse el trabajo de McDonough, G. P. (2010). "Why dissent is a vital concept in moral education". Journal of Moral Education. Vol. 39, $\mathrm{n}^{\circ}$ 4. December, pp. 421 y ss.

${ }^{20}$ En este sentido hay que entender el proyecto de Durkheim de integrar los valores de la revolución francesa en un nuevo orden moral, vinculado de estrecha forma a las necesidades de una sociedad industrial y susceptible de aceptación mayoritaria por parte de los ciudadanos. Ver, Durán Vázquez, J. F. (2008). "La educación moral durkheimiana y la crisis de las esfera educativa en el mundo tardo-moderno". Nómadas. Vol. 17, $\mathrm{n}^{\circ} 1$, p. 2.

${ }^{21}$ Pereira, G. (2011). "Idealización del sujeto y políticas sociales". Sistema, $\mathrm{n}^{\circ}$ 222. Julio, p. 117. Es interesante, en relación a nuestro planteamiento, su aproximación a los rasgos esenciales del paradigma centrado en el reconocimiento, construido por Axel Honneth.

${ }^{22}$ Lecaldano, E. (2011). "Amartya Sen e Adam Smith: relazioni globali e giustizia". Rivista di Filosofia. Vol. CII, n 2. Agosto, p. 263. 


\section{La educación moral}

Entremos ahora en el comentario de las ideas que Durkheim expone en La educación moral, en las que queremos centrarnos en este trabajo. Digamos, ante todo, que su posición de partida en estas lecciones que impartió en la Universidad de la Sorbona, entre 1902 y 1903, consiste en afirmar la existencia de una moral en todo orden social. Para él no existe sociedad alguna que pueda mantenerse en pie sin este componente fundamental. En ese sentido, sostiene que, pese a que "se ha dicho alguna vez que los pueblos primitivos no tenían moral", esto no era otra cosa que "un error histórico. No hay pueblo que no tenga su moral: sólo que la de las sociedades inferiores no es la nuestra. Lo que caracteriza a aquella es precisamente que es esencialmente religiosa"23. Ha de existir, por tanto, una adecuación entre orden social y el entramado de obligaciones en el que se concreta la moral. Este será uno de los aspectos en los que Durkheim insistirá más a lo largo de esta obra, tal como lo había hecho en otros trabajos bien conocidos, en particular El suicidio (1897).

Por otra parte, no hemos de dejar pasar que la alusión a otras sociedades como "inferiores", resulta hoy inaceptable o, cuando menos, chocante; sobre todo por lo que tiene de adscripción de aquellas a un supuesto momento evolutivo anterior a aquel en el que se encuentran las sociedades occidentales. Sin embargo, más que centrarnos en esta alusión, que tanto debe a los tópicos evolucionistas que imperan en la época, habría que interpretar el texto de Durkheim en lo que tiene de positivo, concediendo mayor importancia al reconocimiento que se hace en él de la moralidad como un hecho universal.

Así pues, no existe una sociedad sin moral y ésta se concreta en cierto número de reglas aceptadas por un determinado colectivo. Al mismo tiempo, no podemos dejar de tomar en cuenta la importancia de la relación entre moral y religión, que Durkheim juzga particularmente estrecha en las sociedades que él considera menos evolucionadas $\mathrm{o}$, por expresarlo de otro modo, estructuralmente menos complejas ${ }^{24}$. Es incuestionable que tales afirmaciones no cuadran en absoluto con la idea actual de lo políticamente correcto. En todo caso, para él, "hay un carácter común a todas las acciones que llamamos comúnmente morales, y es que todas son conformes a reglas preestablecidas. Conducirse moralmente es obrar siguiendo una norma que determina la conducta a tener en el caso dado, incluso antes de que necesitemos tomar una opción"25.

Sin embargo, la moral no se concreta jamás en un único conjunto de preceptos, comunes a todas las sociedades, ni mucho menos puede encerrarse en una única fórmula de validez universal. El conjunto de reglas en que se fija, presupone un entramado de

${ }^{23}$ Durkheim, E. (1934). L'éducation morale. Paris: Librairie Félix Alcan. En este trabajo, para facilitar las consultas al lector, citaremos la obra siguiendo la versión española a que hacemos referencia a continuación. Durkheim, E. (2002). La educación moral. Madrid: Trotta, p. 69.

${ }^{24}$ Cfr. Rossi, P. (2011). "Nascita e metamorfosi della filosofía della storia". Rivista di filosofia. Vol. CII, no 3. Dicembre, pp. 501 y ss.

${ }^{25}$ Durkheim, E. La educación moral. Edic. Cit., p. 84. 
valoraciones y experiencias que, a través de determinadas estrategias de aplicación, puede articularse con la realidad, permitiendo acciones que resultan coherentes con aquello que en una sociedad determinada se considera ineludible tomar en consideración.

Pero ninguna norma puede ser omnicomprensiva y situarse por encima de la variedad de culturas existente. En este sentido, Durkheim pone de relieve que "la mayoría de los moralistas, en efecto, presentan la moral como si cupiese toda entera en una fórmula única y muy general; por ello precisamente admiten con tanta facilidad que la moral por entero reside en la conciencia individual, y que un simple vistazo al interior de nosotros mismos basta para descubrirla. Esta fórmula la expresan de maneras diferentes: la de los kantianos no es la de los utilitaristas, y cada moralista utilitarista tiene la suya. Pero, de cualquier modo que se la conciba, todo el mundo pretende asignarle el lugar eminente. Todo el resto de la moral sólo sería la aplicación de este principio fundamental" 26 .

En concreto, el kantiano es generalmente considerado como el intento más logrado que la historia del pensamiento occidental ha conocido, a la hora de elaborar una fórmula que genere y permita expresar en cada caso concreto el sentido del juicio moral sobre el mismo. Y aún así, pese a la aparente fuerza que podemos atribuir a un principio semejante, lo cierto es que no puede considerarse como el elemento clave para definir la moralidad de un acto, puesto que aleja la valoración de éste de la situación concreta en que tal acto se produce. Tampoco es posible aceptar que su validez es universal, pues, como ya hemos dicho, para Durkheim, la moral se basa en contenidos culturales específicos y responde a condiciones sociales concretas. Como él mismo había señalado en otro lugar, en realidad la ética kantiana no pasa de ser un mero juego conceptual, al que es necesario contraponer una visión anclada en la moralidad entendida como realidad social ${ }^{27}$. Estos son los argumentos básicos de Durkheim para criticar el formalismo moral ${ }^{28}$.

Por ello, Durkheim hace hincapié en que "tal concepción invertiría las verdaderas relaciones de las cosas. Si observamos la moral tal como existe, vemos que consiste en una infinidad de reglas especiales, precisas y definidas, que fijan la conducta de los hombres para las diferentes situaciones que se presentan más frecuentemente" 29 . Estas reglas han de ser aprendidas pues, a la base de las mismas, hay más experiencias culturales que determinaciones de origen natural.

El presupuesto del que parte es considerar que el comportamiento de los individuos en la sociedad requiere la existencia de reglas y el conocimiento de éstas, así como de la forma en qué aplicarlas, se asimila a través de la experiencia. De hecho, la reitera-

${ }^{26}$ Ibídem, p. 84.

${ }^{27}$ Dukheim, E. "Définition du fait moral", Durkheim, E. (1975). Textes, vol. 2. Religion, morale, anomie. Paris : Minuit, pp. 257-288.

${ }^{28}$ Cfr. Ibanez-Noe, J. (2011). "The Idea of Vocation. Toward a moral-philosopical teory". Philosophy today. Vol. 55, n². Summer, p. 149.

${ }^{29}$ Durkheim, E. La educación moral. Edic. Cit., p. 85. 
ción de un comportamiento basado en reglas facilita su eficaz asimilación. Tal como él mismo lo expresa, "la moralidad supone (...) una cierta aptitud para repetir los mismos actos en las mismas circunstancias $\mathrm{y}$, por consiguiente, implica un cierto poder de contraer unos hábitos, una cierta necesidad de regularidad. La afinidad del hábito y de la práctica moral es tal que todo hábito colectivo presenta, casi invariablemente, algún carácter moral ${ }^{\prime 30}$.

Pero, más allá de esto, ¿cómo se definen e imponen las reglas? Para Durkheim la explicación de tales procesos no puede obviar la existencia de individuos que están revestidos de la autoridad necesaria para que su conducta sea tenida por modélica y, por tanto, merecedora de reiteración e imitación. Son aquellos que de uno u otro modo, están investidos de ese elemento, la autoridad, al que antes ya hemos hecho mención. En esa misma línea, es importante hacer notar ahora que, a su juicio, "por autoridad debemos entender el ascendiente que ejerce sobre nosotros todo poder moral que reconocemos superior a nosotros. En razón de este ascendiente actuamos en el sentido que nos es prescrito, no porque el acto así exigido nos atraiga, no porque seamos propensos, como consecuencia de nuestras disposiciones internas naturales o adquiridas, sino porque hay, en la autoridad que nos lo dicta, un no se qué que nos lo impone. En esto consiste la obediencia consentida" ${ }^{\prime 3}$. En ese sentido, interesa recalcar aquí que, en un orden social laico y racional, dicha autoridad emana de la propia sociedad, cuyos valores aparecen encarnados en determinados individuos ${ }^{32}$.

Se trata de conseguir que la regla moral sea respetada, sin que para ello resulte necesario imponerla mediante el ejercicio de un poder constrictivo que actúa desde instancias superiores al individuo, arrinconando su conciencia moral y dejando fuera de juego su libertad. Las pasiones humanas sólo pueden detenerse o encauzarse ante el poder de una moral que los individuos hacen suya y respetan ${ }^{33}$. Por esto tampoco debemos dar lugar a equívocos, ya que Durkheim entiende que "la libertad no puede identificarse con la liberación de todas las sujeciones; esto es la anomía, en la cual los individuos no son libres, pues están encadenados a sus propios deseos inagotables"34. En base a este planteamiento, considera nuestro pensador que constituye un error interpretar la libertad como una realidad que se opone de plano a la autoridad moral. Para él, la autoridad moral es imprescindible para el buen funcionamiento de la sociedad y es la propia sociedad la que hace posible, en mayor o menor grado, la libertad. Así, cuando hace referencia al significado del término autoridad, nos dice que "es un carácter del cual un ser real o ideal se halla investido respecto a determinados individuos, y por ese mero hecho es considerado por estos últimos como dotado de poderes superiores a los que ellos se atribuyen a sí mismos. Poco importa por otra parte que estos po-

\footnotetext{
${ }^{30}$ Ibídem, p. 87.

${ }^{31}$ Ibídem, pp. 88-9.

32 Durán Vázquez, J. F. Op. Cit., p. 3.

${ }^{33}$ Durkheim, E. (1967). De la división du travail social, Paris : PUF, pp. 16 y ss.

${ }^{34}$ Giddens, A. El capitalismo y la moderna teoría social. Edic. Cit., p. 200.
} 
deres sean reales o imaginarios: basta que estén representados en las mentes como reales" 35 .

En definitiva, es real, en la sociedad, todo aquello que es percibido por los actores sociales como real. Como se recordará, esto es a grandes rasgos lo que William Thomas enunciará en 1928, formulando sintéticamente la idea que había expresado previamente Durkheim en el teorema que le hará célebre. Es ésta una de las muchas muestras que podríamos traer aquí a colación, del carácter proteico que poseen las ideas del pensador francés.

Antes de continuar nuestro comentario, es necesario poner de relieve que el análisis sociológico del fenómeno moral que realiza no conlleva aparejada ninguna apología del autoritarismo. En primer término, porque, como él mismo se encarga de dejar claro, "para que la regla sea obedecida como debe, es preciso que la respetemos por sí misma, no para evitar tal resultado desagradable, tal castigo material o moral, o para obtener la recompensa; hemos de acatarla simplemente porque debemos respetarla, abstracción hecha de las consecuencias que nuestra conducta pueda tener para nosotros. Hemos de obedecer el precepto moral por respeto a él, y por esta sola razón"36. Este planteamiento, fácil resulta advertirlo, tiene una considerable importancia desde el punto de vista pedagógico. En efecto, la educación, que ha de tener a su juicio una función integradora, no cumpliría de forma adecuada su cometido si contribuyera a formar individuos incapaces de ubicarse en el momento presente ni de interactuar de modo positivo con la realidad social en que viven. Frente a todo idealismo pedagógico, ha de subrayarse, hoy más que nunca, la pertinencia de este imperativo que Durkheim plantea a educadores e instituciones educativas. Por añadidura, la educación ha de inculcar en los individuos la confianza en el logro de sus objetivos, a través del cumplimiento de determinados compromisos. En esto se cifra el deber de los ciudadanos y, a propósito de éste, Durkheim indica de forma tajante que "no se trata de escrutar un futuro siempre oscuro e indeciso; tratamos de saber lo que está prescrito: si el deber ha hablado, no hay más que obedecer" 37 .

El conocimiento de la regla moral y el acomodo a ella de nuestra conducta, confiere seguridad a la acción y transmite certeza al individuo. Éste sabe que ha de obedecerla, pero siente que, al hacerlo, se obedece también a sí mismo. No experimenta la vigencia de la regla como una traición a su libertad, sino como la única posibilidad de alcanzar cierta autorrealización ${ }^{38}$. En este punto advertimos que Durkheim parece partir de una

${ }^{35}$ Durkheim, E. La educación moral. Edic. Cit., p. 135.

${ }^{36}$ Ibídem, pp. 89-90.

${ }^{37}$ Ibídem, p. 90.

${ }^{38}$ Es interesante subrayar, pese a todas las objeciones que desde otras perspectivas puedan hacerse a la posición de Durkheim, la sintonía que podemos encontrar entre sus conclusiones y los planteamientos de la teoría del reconocimiento de Axel Honneth. Para este último, "sin la suposición de un cierto grado de autoconfianza, de autonomía garantizada por ley y de seguridad sobre el valor de las propias capacidades no es imaginable el alcance de la autorrealización, entendiendo por autorrealización un proceso de realización espontánea de los objetivos existen- 
consolidada certeza en la validez última de los principios que rigen la acción colectiva que hoy nos resulta extraña, ya que el relativismo cultural, que él aceptó en cierta medida, aunque evitando siempre que su hipertrofia destruyera la fundamentación de su filosofía social, nos ha conducido a lo que parece ser un punto de no retorno. Desde él, toda concepción que haga gala de certezas similares a las que Durkheim pone sobre el tapete nos parece hoy inadecuada. Sin embargo, a la base de la misma no hay ningún dogmatismo, sino un juicio que posee una fundamentación sociológica. Se trata de principios que tienen una vigencia circunscrita por factores sociales e históricos. Tales principios tienen esa base concreta y determinable. No provienen de ningún credo o fe que pretenda situarse por encima del tiempo ${ }^{39}$.

En este sentido, su exaltación de la disciplina es, al mismo tiempo y sobre todo, defensa de la autodisciplina, considerada asimismo por él como factor clave en la educación ${ }^{40}$. Defiende, por tanto, que "el sentido de la regularidad y el sentido de la autoridad son sólo dos aspectos de un mismo estado de espíritu más complejo, que podemos llamar espíritu de disciplina. El espíritu de disciplina, he aquí entonces la primera disposición fundamental de todo temperamento moral" ${ }^{\text {41 }}$. En ella encuentra el individuo la fuerza necesaria para superar las dificultades entre las que su vida se desenvuelve. Sin embargo, son necesarias convicciones firmes y no vacuidad, evanescencia o ambigüe-

ciales elegidos por uno mismo". Honneth, A. (2010). Reconocimiento y menosprecio. Sobre la fundamentación normativa de una teoría social. Madrid: Katz Editores, p. 31.

${ }^{39}$ De la actualidad de los planteamientos de Durkheim, en este terreno, es buena muestra la sintonía con ellos se advierte en el siguiente pasaje de Les étincelles de hasard, de Henri Atlan : "constatar que una ética universal concreta, que se impondría a todos por la sola fuerza de la razón, no existe (¿aún?), no implica necesariamente resignarse al relativismo moral. Otro tipo de universalismo es posible, en el que la razón es una herramienta de diálogo y no un tribunal. No sirve de fundamento último a partir de una tabla rasa, sino de medio de diálogo a partir de experiencias morales diferentes. Desde esta perspectiva, construir con la herramienta de la razón una ética concretamente universal tan sólo puede hacerse a partir de las morales existentes, por racionalizaciones y argumentaciones retóricas.

Contrariamente a las apariencias, esta actitud es la única barrera que permite evitar que el relativismo del conocimiento nos lleve a caer en un nihilismo en el que 'todo vale', rechazando al mismo tiempo un absoluto, cualquiera que sea, planteado abstractamente. Que este absoluto se pretenda racional y científico o revelado, sabemos hoy que el resultado corre el riesgo de ser el mismo: un régimen totalitario con guerra (santa) de exterminación, donde la intolerancia se conjuga con la creencia. Solamente un diálogo con la búsqueda de compromiso entre culturas y tradiciones diferentes, es lo único de lo que podemos esperar que nazca, por construcción progresiva y de forma empírica, sin revelación impuesta ni excomunión, una universalidad fundada en el reconocimiento del otro". Atlan, H. (2003). Les étincelles de hasard. Vol. 2. Athéisme de l'écriture. Paris: Seuil, p. 51.

40 "La disciplina es por sí misma un factor sui generis de la educación; hay en el carácter moral unos elementos esenciales que sólo pueden ser aportados por ella. Sólo mediante ella podemos enseñarle al niño a moderar sus deseos, a limitar sus apetitos de todo género, a limitar y, por eso mismo, a definir los objetivos de su actividad; y esta limitación es condición de felicidad y de salud moral". Durkheim, E. La educación moral. Edic. Cit., p. 100.

${ }^{41}$ Ibídem, p. 93. 
dad, para que esa función pueda ser desempeñada de forma eficaz. Es necesaria, de igual manera, una clara definición del horizonte de acción y las posibilidades concretas que los individuos pueden materializar en su existencia. "He aquí -nos dice- por qué las épocas como la nuestra, que han conocido el mal del infinito, son necesariamente épocas tristes. El pesimismo acompaña siempre las aspiraciones ilimitadas" "42; una afirmación cuyo calado se amplifica si la referimos al momento actual, en el que confrontan una y mil veces, con resultados en ocasiones catastróficos para los sujetos implicados, unas expectativas sin límites con la obstinada resistencia de la realidad a dejarse permear por ellas. El reto que la tarea de encontrar formas de negociación entre deseo y realidad plantea a la educación, entendida en su más amplio sentido, es incuestionable. Hay que poner de relieve, además, que participa Durkheim asimismo del prejuicio epocal característico de su tiempo, aunque no específico del mismo, a propósito de las pasiones. Disciplinar el cuerpo, en todas sus dimensiones, es una cuestión clave en su pensamiento. No obstante, el objetivo no es la represión sin más de las pasiones, sino -en una línea que nos recuerda la teoría freudiana de la sublimación- la utilización positiva de la energía que de ellas proviene. Sólo así es posible una satisfacción ordenada de las pasiones.

En este sentido, y por lo que respecta a la educación, la valoración positiva de la disciplina permite a Durkheim defender una teoría según la cual, la autolimitación de las pasiones y la canalización de las energías que derivan de ellas, resultan imprescindibles para que el individuo pueda aspirar a cierto nivel de felicidad que, sin esa autocontención, sería impensable. A su entender, "el conjunto de las reglas morales forma alrededor de cada hombre una especie de barrera ideal, al pie de la cual la ola de las pasiones humanas viene a morir sin poder ir más lejos. Y precisamente porque están contenidas es posible satisfacerlas" $"$. En otros términos, rodear las pasiones de un contorno definido y preparar a los individuos para que lo reconozcan y sepan enfrentarse positivamente a él, es lo que hace viable su materialización.

\section{Lo individual y lo colectivo en la educación moral}

Más que en ningún otro, en el ámbito de la moral puede reconocerse no sólo la complejidad del funcionamiento del orden social, sino la necesidad ineludible que se da en él de encontrar un equilibrio entre apertura a lo novedoso y conservación de lo que ha soportado el embate que supone el contraste con la temporalidad. "Como las reglas morales son todavía más inmutables que las demás, aprender a actuar moralmente es también aprender a comportarse consecuentemente, según principios constantes, superiores a los impulsos y las sugestiones fortuitas" ${ }^{24}$. Durkheim puede, a partir de esta convicción, profundizar en sus reflexiones, analizando todas las direcciones que acierta a contemplar, sobre la importancia social del comportamiento moralmente fundamentado. En este sentido, empieza señalando que "los actos que persiguen fines

\footnotetext{
${ }^{42}$ Ibídem, p. 98.

${ }^{43}$ Ibídem, p. 99.

${ }^{44}$ Ibídem, p. 103.
} 
exclusivamente personales del sujeto que los realiza no tienen valor moral, sean cuales fueren" $"$. Con ello deja claro el sentido social que confiere al comportamiento moral. Desde esta perspectiva, el puro interés personal deforma la acción y le hace perder el rango moral. "Los actos prescritos por las reglas de la moral presentan todos este carácter común: persiguen fines impersonales" $"$. De forma aún más contundente, afirma que "los fines morales son, pues, los que tienen por objeto una sociedad. Actuar moralmente es actuar con vistas a un interés colectivo" ${ }^{47}$. Por tanto, es necesario encuadrar las aspiraciones personales en el contexto de los ideales colectivos. La educación ha de asumir entre sus objetivos primordiales contribuir de manera decisiva a esa tarea.

Sobre la constancia de las reglas morales, a pesar de su origen y significación social e histórica, nos ofrece un elocuente ejemplo, referido a la capital francesa. A través de éste, podemos observar en un contexto concreto cómo interactúan los parámetros entre los que ubican sus reflexiones sobre la educación moral. Nos dice así que "la población de París se renueva incesantemente; nuevos elementos afluyen sin cesar. En los parisienses de hoy hay muy pocos que descienden de los parisienses de principios de siglo. Pero la vida social de París presenta actualmente los mismos caracteres esenciales que hace cien años, sólo están más acusados: idéntica tendencia relativa a los delitos, a los suicidios, a la nupcialidad, idéntica debilidad relativa a la natalidad; las proporciones entre los estratos de edad son análogas. Por tanto es la propia actuación del grupo la que impone sus semejanzas a los individuos que van entrando. Es la mejor prueba de que el grupo es algo distinto del individuo" 48 .

Con esto se nos viene a decir que el grupo social tiene una entidad y un valor que trascienden ampliamente lo individual. En él surgen tendencias que suponen una apertura hacia lo diferente de los sujetos que las profesan, pero esos posibles elementos novedosos se contrarrestan en todo momento con otros que inciden sobre la consolidación de diversas orientaciones que nos retrotraen y proyectan hacia el pasado. Por esta razón, su condena del individualismo no se realiza tanto como resultado de su enjuiciamiento moral, sino más bien como consecuencia de una constatación sociológica. "Sin duda, la conducta moral siempre ha sido concebida necesariamente como productora de consecuencias útiles para algún ser viviente y consciente, cuya felicidad aumenta o cuyos sufrimientos disminuye. Pero no existe sociedad que haya admitido que el ser cuyos intereses servía fuera el mismo individuo que actuaba. El egoísmo ha sido universalmente clasificado entre los sentimientos amorales" ${ }^{\text {"49 }}$. El egoísmo fomenta una errónea relación con lo social, que hace caer al individuo en la desazón, en la anomía y lo sitúa en el camino de los mayores riesgos. Sin embargo, nuestra civilización ha construido sus fundamentos precisamente sobre el desarrollo del individualismo. Con la insistencia de quien está convencido de sostener ideas que pueden tener una gran relevancia para afrontar la encrucijada histórica en se ubica, Durkheim se ha ocupado

\footnotetext{
${ }^{45}$ Ibídem, p. 112.

${ }^{46}$ Ibídem.

${ }^{47}$ Ibídem, p. 113.

${ }^{48}$ Ibídem, p. 116.

${ }^{49}$ Ibídem, p. 117.
} 
con denodado interés en mostrar "que la necesidad de contenerse en unos límites determinados era reclamada por nuestra propia naturaleza, es decir, que allí donde falta este límite, allí donde las reglas morales no tienen la autoridad necesaria para ejercer sobre nosotros su acción reguladora en el grado requerido, vemos a la sociedad presa de una tristeza, de un desencanto, que se traducen en la curva de suicidios" ${ }^{\$ 50}$. Nos muestra de esta manera, recurriendo al ejemplo más extremo, el impacto que tiene la ausencia o debilidad de convicciones morales sobre el individuo y la sociedad. En efecto, para él existe una correlación entre el aumento en el índice de suicidios y la anomía creciente de los individuos en la sociedad moderna ${ }^{51}$. En ella, diversos factores han incidido sobre las formas religiosas tradicionales, que proporcionaban cohesión y absorbían tensiones, provocando el declive de su influencia, mientras que aún no se han puesto en obra otros mecanismos que sustituyan a la religión en la tarea de apuntalar los mismos fines colectivos ${ }^{52}$. Es imprescindible, por tanto, la contribución de todos aquellos que puedan difundir entre la población los nuevos valores que avalan el orden social en un momento en que la religión tradicional ocupa ya un segundo plano.

La importancia clave de lo social es remarcada por Durkheim desde todos los ángulos imaginables. Por este motivo insiste una y otra vez en que si queremos comprender el sentido de la moral hemos de atender a factores sociales. Tal como él mismo nos dice, "la moral de cada pueblo está directamente en relación con la estructura del pueblo que la practica. El vínculo es tan estrecho que, dados los caracteres generales de una moral observada por una sociedad, exceptuando casos anormales y patológicos, podemos inferir la naturaleza de esta sociedad, las partes de las que se compone y la manera en que están organizadas",53.

En resumen, como ya se ha apuntado, desde todas las perspectivas posibles, Durkheim quiere hacer constar la decisiva relevancia de los factores sociales, frente al excesivo hincapié que en su época se hacía en las posibilidades exclusivamente individua1 es ${ }^{54}$. El equilibrio vital que el individuo necesita para realizarse, precisa en todo momento del sostén colectivo. Por ello, de perseguir el imposible de una realización personal que se ha de lograr frente a la sociedad en lugar de apoyándose en ella, se derivan a su juicio muchas de las tragedias de su época, que en cierto modo, también es la nuestra. Frente a esa aporía en la que nos ha situado el individualismo propio de la

${ }^{50}$ Ibídem, p. 120.

${ }^{51}$ Giddens, A. El capitalismo y la moderna teoría social. Edic. Cit., pp. 154-5.

${ }^{52}$ Espert, N. Ma . (2008). "De clásicos o panteones ajenos: una aproximación a la contemporaneidad de la distinción durkheimiana entre lo sagrado y lo profano". Reflexiones. Vol. $20, \mathrm{n}^{\circ}$ 4, p. 10 .

${ }_{53}$ Durkheim, E. La educación moral. Edic. Cit., p. 134.

54 "Dependemos forzosamente del medio que nos rodea; nos penetra, se mezcla con nosotros. Por consiguiente, en nosotros hay algo distinto de nosotros, y solamente porque estamos sujetos a nosotros mismos estamos sujetos a algo distinto de nosotros. Incluso podemos decir más: el egoísmo absoluto es una abstracción irrealizable, puesto que, para vivir una vida puramente egoísta, nos haría falta despojarnos de nuestra naturaleza social, lo que es tan imposible como saltar más allá de nuestra sombra”. Ibídem, p. 122. 
cultura contemporánea, seguimos buscando algún horizonte en el que lo que percibimos como disociado pueda encajar en alguna suerte de unidad. En este sentido, él mismo, ofreciéndonos una curiosa proyección de sus afirmaciones, llega a comentar que "el culto del yo y el sentimiento de lo infinito son con frecuencia contemporáneos", añadiendo, para sorpresa de muchos, que "el budismo es la mejor prueba de esta solidaridad" ${ }^{\prime \prime 5}$.

¿Cómo entender que el desapego en relación a la subjetividad, propio del budismo, conlleva al mismo tiempo un culto al yo? Es una idea interesante que, bien pensada, vendría a incidir sobre la disolución de la identidad como única forma, paradójica por supuesto, de realizar el yo. En esta línea, la culminación nos coloca en situación de vislumbrar la destrucción de la subjetividad. Esto tiene como contrapunto la percepción de la infinitud, que es concebida como resolución positiva del fracaso en la construcción de la subjetividad. Sin embargo, Durkheim correlaciona, siguiendo en este punto las líneas básicas del pensamiento griego clásico, infinitud con ausencia de límites y, por tanto, con imperfección.

\section{Lo bueno y lo debido}

Otra de las características de la obra sobre cuyo contenido venimos reflexionando, es que su autor llega en ella a perfilar con notable nitidez el calado de la aporía que encierra la relación entre el bien y el deber. En efecto, para él, los moralistas de todos los tiempos se han confrontado de forma equívoca con la cuestión de la relación entre bien y deber.

"Para unos el bien es la noción primitiva de la que se deriva el deber; tenemos, dicen, el deber de ajustarnos a la regla porque el acto que prescribe es bueno. Pero, entonces, la idea de deber se eclipsa e incluso desaparece completamente. Hacer algo porque nos gusta, porque es bueno, no es más que hacerlo por deber. El deber, al contrario, implica casi necesariamente la idea de un esfuerzo requerido por una resistencia de la sensibilidad; en el fondo de la noción de obligación subyace la noción de un apremio moral. Otros, al contrario, han tratado de deducir el bien del deber y han dicho que no había otro bien más que cumplir el deber. Pero, entonces, inversamente, la moral se despoja de todo lo que es aliciente, de todo lo que habla al sentimiento, de todo lo que puede provocar las espontaneidades de la acción, para convertirse en una consigna imperativa puramente coercitiva a la que hemos de obedecer sin que los actos que nos impone correspondan a nada en nuestra naturaleza, sin que tengan para nosotros interés de ninguna clase" ${ }^{, 56}$.

Como él mismo se encarga de dejar claro, si planteamos el problema en tales términos, se convierte en una aporía insoluble. Por el contrario, frente a este enfoque, resulta mucho más positivo considerar que el bien y el deber son dos aspectos diferentes de una misma realidad, "pues, entonces, lo que forma su unidad no es que éste sea un

\footnotetext{
${ }^{55}$ Ibídem, p. 123.

${ }^{56}$ Ibídem, pp. 142-3.
} 
corolario de aquél, o inversamente; es la misma unidad del ser expresada en modos de acción diferentes" ${ }^{, 57}$. Así, en un contexto interpretativo en el que la sociedad siempre es concebida como una entidad específica y nunca como el mero resultado aritmético de adicionar los elementos que la componen ${ }^{58}$, Durkheim puede plantear con la concreción requerida las pautas que, a su juicio, deben regir la tarea educativa. Desde esta perspectiva, afirma que "el medio de formar moralmente al niño no es repetirle, incluso con calor y convicción, un cierto número de máximas muy generales, válidas para todos los tiempos y todos los países, sino de hacerle comprender su país y su tiempo, de hacerle sentir las necesidades, de iniciarle en su vida, y de prepararle así a tomar parte en las obras colectivas que le esperan"

Por otro lado, subrayando la importancia crucial de la división del trabajo, viene a enfatizar de análoga forma la conveniencia de formar a los individuos en la necesidad de cooperar unos con otros ${ }^{60}$. Frente a esa necesidad de cooperación, nos encontramos con cierta "tendencia natural" en el niño a dejarse abatir por la frustración y reaccionar de forma colérica, cuando lo que acaece no se acomoda a sus deseos. La educación ha de ayudar al niño a recorrer la distancia que media entre ese tipo de reacciones y aquellas otras que pueden permitirle definir y lograr sus objetivos, al mismo tiempo que realiza una contribución significativa a la sociedad en que vive ${ }^{61}$.

Al expresar la decisiva importancia del cambio que la educación ha de producir en el educando, Durkheim establece un paralelismo entre el niño y el hombre primitivo, que no deja de ser revelador de la persistencia e influjo, no siempre positivos, de una cierta mentalidad. Para ésta última, la educación ha de empeñarse ante todo en la tarea de domesticar los instintos salvajes que residen en el niño, al igual que las naciones civilizadas tienen la obligación moral de poner bajo su tutela las sociedades primitivas, para que éstas salgan de una vez por todas del estado de incivilidad en que se encuentran. A pesar de ello, hemos de reconocer que, contorneando con habilidad los escollos más peligrosos de esa recusable ideología, Durkheim se esfuerza en neutralizar los efectos más destructivos que pueden detectarse en ella, insistiendo en sus planteamientos básicos acerca del valor integrador de la educación moral. Aún así, no deja de lado determinados aspectos de la psicología infantil que, de cara a la tarea educativa, tienen en su opinión una gran relevancia. De esta manera, detecta en ella, de forma análoga a lo que sucede en la denominada mentalidad primitiva, una tendencia al tradicionalismo y una receptividad a la sugestión, que, paradójicamente, pueden convertirse en útiles aliados del educador ${ }^{62}$. Esto no significa que Durkheim considere que la tarea educativa sea una labor de domesticación y que no deba respetar la libertad del educando. Por el contrario, no deja de poner de relieve que, "lejos de creer que la acción del maestro o de los padres no corre nunca el riesgo de ser excesiva, algunas medidas son indispen-

\footnotetext{
${ }^{57}$ Ibídem, p. 143.

${ }^{58}$ Ibídem, p. 148.

${ }^{59}$ Ibídem, p. 162.

${ }^{60}$ Ibídem, p. 169.

${ }^{61}$ Ibídem, pp. 170-1.

${ }^{62}$ Ibídem, p. 171.
} 
sables para proteger frente a ellos la libertad del niño". Insiste, en consecuencia, en que "una de las precauciones más eficaces que pueden ser tomadas a este respecto es impedir que los niños sean formados en un único solo y único medio, y, más aún, por una sola y única persona. Es una de las numerosas razones que hacen insuficiente la educación doméstica. El niño educado exclusivamente en su familia se convierte en cosa suya; reproduce todas las particularidades, todos los rasgos y hasta los tics de la fisonomía familiar, pero no podrá desarrollar su fisonomía personal. La escuela le libera de esa dependencia demasiado estrecha" ${ }^{\text {63 }}$. Ha de preservarse, en consecuencia, la libertad del niño, fomentando para ello las posibilidades que este tiene de elegir y, por tanto, de elegirse. Ni el peso de la influencia familiar ni la presencia ineludible de las reglas morales, deben anular la libertad del educando.

Considerado desde una perspectiva más general, puede apreciarse que el planteamiento de Durkheim aboca a una diáfana conclusión: "Es indispensable que haya reglas; es malo que todo esté regulado. Todas las acciones del adulto no están sometidas a la reglamentación de la moral; las hay en las que él tiene la facultad de hacer o de no hacer, o de hacer como él entiende, porque, en una palabra, no son relevantes en cuanto a la apreciación moral"

Siempre encontramos en Durkheim a un defensor de la libertad pues, para él, el sentido de la conducta moral reside en que emana de un comportamiento libre, por más que esta libertad sólo pueda ser definida dentro del encuadre de coacciones e interacciones sociales. "En las condiciones morales actuales, en que el individuo está interesado en actuar por sí mismo y jugar un papel personal en la vida colectiva, una reglamentación tan avasalladora no puede dejar de tener sobre la moralidad del niño la peor influencia. Así que cuando no lo convierte en un rebelde, hace de él un deprimido moral"65. Extremos ambos que considera necesariamente evitables a través de la educación. La educación, o mejor, las instituciones educativas, han de partir, a su juicio, de la voluntad de ayudar a los educandos a quedar liberados de dicho dilema. La aporía que tienen que tener presente, no es la que forman rebelión o depresión. El educador no tiene por qué elegir entre forjar insumisos o contribuir a crear una legión de seres adocenados y pasivos frente a lo que les rodea. Podría criticarse a Durkheim que ponga un acento excesivo en la integración social de los individuos. Sin embargo, no podemos dejar de reconocer que, si lo hace así, es convencido de que la integración positiva en el orden social es la clave para superar la aporía a la que hace un momento nos referíamos ${ }^{66}$.

Resta señalar, por último, que se opone de forma contundente a que, para conseguir dicho objetivo, se empleen castigos corporales, en especial cuando estos se practican en el interior de las instituciones educativas. Con gran acierto, hace notar que tales castigos tendrían como consecuencia la destrucción de la autoestima y el minado de la

${ }^{63}$ Ibídem, p. 180.

${ }^{64}$ Ibídem, p. 186.

${ }^{65}$ Ibídem, p. 187.

${ }^{66}$ Cfr. Boyd, D. (2011). "Learnign to leave liberalism ... and live with complicity, conundrum and moral chagrin". Journal of Moral Education. Vol. 40, n 3, pp. 33 y ss. 
subjetividad. El individuo sometido a la humillación pública quedaría herido, precisamente en aquello que ha de constituir el punto de partida de la sensibilidad moral. En un momento en que los castigos corporales constituyen un viejo y desafortunado recuerdo, es en esto en lo que debemos poner el énfasis, ya que, sin respeto a uno mismo y sin apoyo por parte de la colectividad, no se puede construir una moral que pretenda garantizar el respeto mutuo en el seno de la sociedad ${ }^{67}$. Sería una completa insensatez no convenir con él, cuando hace hincapié en que, por el contrario, el castigo, de producirse, ha de tener por función evidenciar el fundamento racional de la norma social y la importancia de respetarla ${ }^{68}$. Esto ha de ser así, si queremos hacer posible la libertad del individuo, su impulso hacia la autorrealización y el mantenimiento de un orden social en el que todos pueden albergar similares aspiraciones. Que en la sociedad actual se hayan producido profundas transformaciones en el ámbito familiar o laboral, con respecto a lo que estos fueron en el período de la III $^{a}$ República francesa, es algo obvio. Sin embargo, esta circunstancia, en contra de lo que algunos sostienen ${ }^{69}$, no convierte al discurso durkheimiano sobre la educación en trasnochado e inoperante. No hay que olvidar, a este respecto, que él mismo advierte ya tales tendencias en sus estudios sobre la familia, los cambios en la moral sexual o las transformaciones en el mundo del trabajo $^{70}$. Entonces y ahora, la educación moral fracasa cuando no consigue inculcar en el educando la relación interna que existe entre lo que debe ser perseguido como bueno y aquello que ha de ser asumido como objeto del deber, cuando deserta de la tarea de contribuir de forma decisiva a la configuración del ethos de los educandos ${ }^{71}$. Si esto es así, es evidente que somos protagonistas y herederos, en nuestros días, de un profundo fracaso educativo.

\section{Conclusiones}

Terminaremos este breve ensayo, exponiendo de forma resumida algunas de las tesis que, partiendo de la lectura de las ideas pedagógicas y éticas de Émile Durkheim, se han sostenido en él.

En primer término, es preciso poner de relieve que el trasfondo de su interpretación de la sociedad nos lo proporciona una concepción organicista de la misma. En ella, la moral constituye una pieza esencial para el mantenimiento y buen funcionamiento del orden social. Estos dos elementos, organicismo e importancia clave de la moral en el orden social, condicionan, para bien y para mal, todo su discurso pedagógico. Es cierto que, para cualquier lector de Durkheim, resulta evidente la continua presencia en su obra de los dos elementos mencionados. Sin embargo, quizá no se haya hecho el sufi-

${ }^{67}$ Durkheim, E. La educación moral. Edic. Cit., p. 211.

${ }^{68}$ Durán Vázquez, J. F. Op. Cit., p. 5.

${ }^{69}$ Ibídem, p. 10.

${ }^{70}$ Ver, por ejemplo, como muestra de ello su ensayo de 1892, "La famille conjugale". Durkheim, E. (1975). Textes. Vol. 3. Foctions sociales et institutions. Paris : Minuit, pp.35-49.

${ }^{71}$ Chiva, O. - Esteve, M. (2008). "Las claves de la educación moral". Ribalta. $\mathrm{N}^{\mathrm{o}} 14$, p. 1. 
ciente hincapié en las consecuencias que, desde el punto de vista de la filosofía de la educación, se desprenden de ellos.

Una de ellas es, sin duda, que la coerción pase a ser un aspecto secundario, externo, frente a la cualitativa importancia inductora de la autoridad moral, que Durkheim considera el elemento interno y determinante.

Otra, que el pensador francés intente ponernos en guardia frente a las consecuencias negativas de la expansión del individualismo en la modernidad. Para él, la más palpable de las mismas es la imparable extensión del vacío moral en las sociedades desarrolladas.

Tampoco es ajena a tales presupuestos, su crítica al liberalismo político, tal como lo entendían y lo siguen entendiendo los partidarios del laissez-faire. Hoy hablaríamos, en ese sentido, más bien de neo-liberales. En todo caso, en lo que se refiere a lo que aquí nos preocupa y ocupa, es importante resaltar el sentido de dicha crítica. Ésta se produce por las consecuencias que las ideas liberales tienen en la implantación de un modelo educativo que mina las posibilidades de integración social de los individuos.

Ha de señalarse, por último, que para Durkheim la moral no se concreta jamás en un único conjunto de preceptos, comunes a todas las sociedades, ni mucho menos puede encerrarse en una única fórmula de validez universal. El conjunto de reglas en que se fija, presupone un entramado de valoraciones y experiencias que, a través de determinadas estrategias de aplicación, puede articularse con la realidad, permitiendo acciones que resultan coherentes con aquello que en una sociedad determinada se considera ineludible tomar en consideración. En tal sentido ha de entenderse su crítica al formalismo moral kantiano.

En definitiva, frente a la imposición de cualquier universalismo abstracto, la educación moral ha de respetar la singularidad y la diferencia, y así contribuir de forma decisiva a la configuración del ethos de los educandos.

\section{Referencias bibliográficas}

ATLAN, H. (2003). Les étincelles de hasard. Vol. 2. Athéisme de l'écriture. Paris: Seuil.

BOYD, D. (2011). "Learnign to leave liberalism ... and live with complicity, conundrum and moral chagrin". Journal of Moral Education. Vol. 40, n 3 .

CHIVA, O. - ESTEVE, M. (2008). "Las claves de la educación moral”. Ribalta. No 14.

DURÁN VÁZQUEZ, J. F. (2008). "La educación moral durkheimiana y la crisis de las esfera educativa en el mundo tardo-moderno". Nómadas. Vol. 17, nº 1.

DURKHEIM, E. (1967). De la división du travail social, Paris : PUF.

DURKHEIM, E. (1975). Textes, vol. 2. Religion, morale, anomie. Paris : Minuit.

DURKHEIM, E. (1975). Textes. Vol. 3. Foctions sociales et institutions. Paris : Minuit. 
DURKHEIM, E. (1934). L'éducation morale. Paris: Librairie Félix Alcan (Vers. Española, DURKHEIM, E. (2002). La educación moral. Madrid: Trotta).

DURKHEIM, E. (2011). Escritos políticos. Barcelona: Gedisa.

ESPERT, N. Ma. (2008). "De clásicos o panteones ajenos: una aproximación a la contemporaneidad de la distinción durkheimiana entre lo sagrado y lo profano". Reflexiones. Vol. 20, $\mathrm{n}^{\mathrm{o}} 4$.

GIDDENS, A. (1977). El capitalismo y la moderna teoría social. Barcelona: Labor.

HONNETH, A. (2010). Reconocimiento y menosprecio. Sobre la fundamentación normativa de una teoría social. Madrid: Katz Editores.

IBANEZ-NOE, J. (2011). "The Idea of Vocation. Toward a moral-philosopical teory". Philosophy today. Vol. 55, nº. Summer.

MCDONOUGH, G. P. (2010). "Why dissent is a vital concept in moral education". Journal of Moral Education. Vol. 39, $\mathrm{n}^{\circ}$ 4. December.

MORALES ZÚÑIGA, L. C. (2009). "Durkheim y Bourdieu: reflexiones sobre la educación". Reflexiones. Vol. 88, $\mathrm{n}^{\circ} 1$ Morales Zúñiga, L. C. (2009). "Durkheim y Bourdieu: reflexiones sobre la educación”. Reflexiones. Vol. 88, nº 1 .

NENG LIN, W. - ENRIGT, R. - KLATT, J. (2011). "Forgiveness as character education for children and adolescents". Journal of Moral Education, vol. 40, ${ }^{\circ} 2$. June.

PEREIRA, G. (2011). "Idealización del sujeto y políticas sociales". Sistema, nº 222. Julio.

ROSSI, P. (2011). "Nascita e metamorfosi della filosofía della storia". Rivista di filosofia. Vol. CII, $\mathrm{n}^{\circ}$ 3. Dicembre.

Correspondencia con el autor

Domingo Fernández Agis

Facultad de Filosofía

Universidad de La Laguna

Campus de Guajara

(38071) La Laguna. Tenerife. España.

e-mail :dferagi@ull.es 